\title{
On the relative importance of customer satisfaction and trust as determinants of customer retention and positive word of mouth
}

Received (in revised form): 16th February, 2003

\section{Chatura Ranaweera}

is Assistant Professor of Marketing at the School of Business, Wilfrid Laurier University, Ontario, Canada. He holds a PhD from the University of Cambridge, UK and a Master of Engineering Management from the George Washington University, USA. His work has appeared or will soon appear in the International Journal of Operations and Production Management and the International Journal of Service Industry Management. He has also presented his work and consulted internationally.

\section{Jaideep Prabhu}

is Assistant Professor of Marketing at the Judge Institute of Management Studies, University of Cambridge, UK. He holds a PhD from the University of Southern California, USA, and has published numerous articles, including in the Journal of Marketing Research.

Chatura Ranaweera School of Business, Wilfrid Laurier University, 75 University Avenue West, Waterloo, Ontario N2L 3C5, Canada.

Tel: +1 519884 0710; e-mail: cranawee@wlu.ca

\begin{abstract}
This study examines the combined effects of customer satisfaction and trust on customer retention and positive word of mouth (WOM). Data from a large-scale survey of fixed line telephone users in the UK confirm that both satisfaction and trust have strong positive associations with customer retention and WOM. Contrary to some assertions in the literature, however, the authors find that the linear effect of satisfaction on retention is much stronger than that of trust. As a driver of WOM, however, trust is only marginally weaker than satisfaction. Furthermore, quantitative analysis, supported by qualitative evidence from the survey, suggests that even a satisfying service recovery process might still be inadequate to prevent loss of trust. Results illustrate, a) the need for firms to develop strategies that focus on building both satisfaction and trust, and $b$ ) that 'satisfactory' service recovery may not be the panacea for all service failures.
\end{abstract}

\section{INTRODUCTION}

Customer satisfaction has traditionally been regarded as a fundamental determinant of long-term customer behaviour. ${ }^{1}$ The more satisfied the customers are, the greater is their retention, ${ }^{2}$ the positive word of mouth $(\mathrm{WOM})^{3}$ (also referred to in the literature as advocacy), and ultimately, the financial benefits to the firms who serve them. ${ }^{4}$ It is no surprise, therefore, that firms seek to increase customer satisfaction. Satisfaction alone, however, does not ensure continued service patronage. ${ }^{5}$ While satisfaction may be one important driver, trust is also likely to influence retention and WOM, both independently and in tandem. This paper incorporates into models of retention and WOM, the influence of trust in addition to the traditional emphasis on satisfaction. In the process, hitherto neglected effects 
are uncovered and some valuable insights into means of building loyal customers are provided.

Meta analysis studies on satisfaction ${ }^{6}$ and trust ${ }^{7}$ show that while satisfaction and trust are closely related, they are conceptually different. Further, some argue that trust is a stronger emotion than satisfaction and that it may therefore better predict retention and WOM behaviour. ${ }^{8}$ Nevertheless, little is known regarding the relative explanatory power of these two constructs. By studying the effects of trust and satisfaction together, the authors seek to shed more light on their relative importance in influencing retention and WOM. Doing so is particularly relevant in the highly competitive business environment where companies are striving to find alternative means of gaining a competitive advantage. Indeed, while the aim of most firms is to strive for 100 per cent customer satisfaction, this is often not feasible. For example, the American Customer Satisfaction Index for the second quarter of the year 2002 shows the cross country, overall index to be only 73 per cent. In this context, the authors believe that identifying alternative means of retaining customers, such as through building trust relationships, is particularly useful.

This study examines the effects of satisfaction and trust on retention and WOM taken separately. The authors believe that studying retention and WOM separately is superior to studying an overall measure of loyalty that combines them because the effects of satisfaction and trust on retention could be different from their effects on WOM. Retention is known to be a behavioural dimension of loyalty, ${ }^{9}$ determined by both positive as well as negative drivers such as switching barriers. ${ }^{10}$ On the other hand, WOM is known to reflect the affective dimension of loyalty, ${ }^{11}$ and is driven by customers' true affect towards the service provider. Combining retention and WOM into one overall measure of loyalty would, therefore, cloud these differing effects. The hypotheses raised are tested in a continuous purchasing setting. A continuous purchasing setting is one where customers maintain long-term contractual relationships with service providers. This setting is distinct, therefore, from the discrete purchasing patterns found in the retail sector.

\section{HYPOTHESES}

Based on a review of the literature, the following set of hypotheses is developed.

Numerous studies in the service sector have empirically validated the link between satisfaction and behavioural intentions and behaviours such as retention ${ }^{12}$ and WOM. ${ }^{13}$ Indeed, this link is fundamental to the marketing concept, which holds that satisfying customer needs and wants is the key to building loyal customers. Further, the importance of satisfaction on retention is so well recognised that some major economies now measure satisfaction at the industry level using large sample surveys to predict customer retention, loyalty (which reflects WOM) and future financial performance. ${ }^{14}$ Thus the expected findings are:

$\mathrm{H}_{1}$ : The higher the level of satisfaction, the higher the level of customer retention.

$\mathrm{H}_{2}$ : The higher the level of satisfaction, the higher the level of positive WOM.

Research suggests that in some cases even satisfied customers may switch ${ }^{15}$ and that it is therefore necessary to look beyond satisfaction toward building 
trust. ${ }^{16}$ This view is consistent with the channels literature, ${ }^{17}$ which shows that firms look at trust to ensure economically viable, long-term relationships. Although the consequences of trust in business-to-business (B-B) relationships have been established, it is not the same with business-to-consumer (B-C) relationships. Much of the existing work in this area tends to be either conceptual $^{18}$ or anecdotal. ${ }^{19}$ Nevertheless, drawing upon the channel relationships literature, ${ }^{20}$ it is hypothesised that:

$\mathrm{H}_{3}$ : The higher the level of trust, the higher the level of customer retention.

Hart and Johnson use anecdotal evidence to argue that firms must establish 'total trust' to ensure true customer loyalty. ${ }^{21}$ Since WOM is often argued to be a key characteristic of truly loyal customers, it is hypothesised that:

$\mathrm{H}_{4}$ : The higher the level of trust, the higher the level of positive WOM.

Some assertions are made to the effect that trust is more important than satisfaction in building loyal customers. ${ }^{22}$ However, the basis for these assertions lies mostly in the channels literature on B-B relationships. In such settings parties invest considerable resources towards relationship building and thus termination of the relationship is often very

expensive. In a $\mathrm{B}-\mathrm{C}$ relationship, the consequences of relationship termination are less significant. Therefore, it is argued that the role of trust is also bound to be less significant in the latter context. Thus:

$\mathrm{H}_{5}$ : Satisfaction will be a better predictor of customer retention than trust.
$\mathrm{H}_{6}$ : Satisfaction will be a better predictor of positive WOM than trust.

\section{METHOD}

The hypotheses generated above were tested on customers of fixed line residential telephones. Qualitative interviews of 40 customers representing different demographic categories were followed by a large-scale survey of 2,850 randomly selected customers from two adjacent towns in South-East England. In order to make the sample more representative of the population, the sample contained both long-term customers (66.6 per cent) and those who had changed companies recently (33.3 per cent). The questionnaire contained both structured and open-ended questions. In the latter, respondents were asked to describe critical events that led to dissatisfaction or loss of trust. This was a probing question based on a procedure recommended in the literature to have a high level of reliability and validity. ${ }^{23}$ The respondents belonged to one of the two premier service providers in the region. The sample was selected based approximately on the prominence of each service provider in the region.

\section{Measures}

Satisfaction, trust, positive WOM and retention were measured using multiple item, seven-point Likert-type scales. Factor analysis confirmed the underlying structure of the measurement items.

Reliability coefficients (Cronbach's $\alpha$ ) for the reflective scales were high

$\left(\alpha_{\text {Sat }}=0.94 ; \alpha_{\text {Trust }}=0.78 ; \alpha_{\text {WOM }}=0.79\right)$.

Retention: a three-item formative scale used in the marketing channels literature was adapted to measure 'propensity to leave' in a B-B 
relationship. The three items measured the likelihood of the respondent leaving the service provider at three different periods in the future - six months, one year and two years respectively. The overall score was a summate of the three weighted items.

WOM: a two-item measure was used reflecting both voluntary recommendation of the service and involuntary recommendation based on the two-dimensional typology, which identified two key types of WOM receiver initiated and sender initiated. ${ }^{24}$

Satisfaction: a three-item measure adapted from a customer satisfaction measure presented in the literature ${ }^{25}$ was used. The measure relied on the conceptual definition of satisfaction as an evaluation of an emotion. One item reflected the emotional dimension and two items reflected the evaluative dimension of the construct.

Trust: the three-item measure reported in the seminal study on the commitment-trust theory of relationship marketing ${ }^{26}$ was adopted. Trust was conceptualised as 'what exists when one party has confidence in a partner's reliability and integrity'. This definition is also consistent with previous definitions of trust as 'willingness to rely on a partner in whom one has confidence', ${ }^{27}$ and the classic view that trust is a 'generalised expectancy held by an individual that the word of another can be relied on'.

\section{ANALYSIS AND RESULTS}

The authors received 461 responses and a valid response rate of 16.2 per cent. There were no significant differences in the response rates for respondents of the two firms. Tests for non-respondent biases were also non-significant at 0.05 level. For the individual tests, missing items were treated as missing completely at random, and excluded list-wise. There were adequate representations of all age categories and both genders. As expected, data showed some deviations from normality. However, only retention scores fell outside $+/-1$ for skewness and kurtosis. The retention scores were transformed using both a square root and $\log$ transformation technique. The log-transformed data were used since they gave the best results for normality and homoscedasticity.

Table 1 illustrates the simple bivariate correlations among the key constructs. Data indicate the significant positive effects of satisfaction and trust on retention and WOM. Next, two regression models for the two dependent variables were built. The resultant models of retention and WOM are shown in Table 2. Regression results showed some shared variance. However, both the condition index and variance inflation factors were within acceptable limits, indicating that, as far as multicollinearity is concerned, there are no causes for great concern.

Model 1 shows that both main effects of satisfaction and trust on retention are significant, confirming Hypotheses $\mathrm{H}_{1}$ $(\beta=0.50, p<0.01)$ and $\mathrm{H}_{2}(\beta=0.15$, $\mathrm{p}<0.01)$. Satisfaction was by far the stronger driver of retention relative to trust, confirming Hypothesis $\mathrm{H}_{5}$.

Model 2 illustrates the regression results for WOM. Both satisfaction and trust had significant positive linear effects on the dependent variable, confirming Hypotheses $\mathrm{H}_{2}(\beta=0.28, p<0.01)$ and $\mathrm{H}_{4}(\beta=0.27, p<0.01)$. Satisfaction was again found to be a stronger driver of WOM than trust, confirming Hypothesis $\mathrm{H}_{6}$. However, unlike in the case of predicting retention, the difference in effects of satisfaction and trust on WOM was marginal ( $\beta_{\text {Satisfaction }}=0.28$ vs $\left.\beta_{\text {Trust }}=0.27\right)$. 
Table 1: Pearson Correlations (Sig. 2-tailed)

\begin{tabular}{lllll}
\hline & $\begin{array}{l}\text { Customer } \\
\text { satisfaction }\end{array}$ & Trust & $\begin{array}{l}\text { Customer } \\
\text { retention }\end{array}$ & Positive WOM \\
\hline Customer satisfaction & 1.000 & & \\
Trust & $0.674^{\star \star \star}$ & 1.000 & \\
Customer retention & $0.596^{\star \star \star}$ & $0.482^{\star \star \star}$ & 1.000 & \\
Positive WOM & $0.462^{\star \star \star}$ & $0.439^{\star \star \star}$ & $0.430^{\star \star \star}$ & 1.000 \\
\hline
\end{tabular}

${ }^{\star * \star}$ Correlation is significant at 0.01 level

Table 2: Results of OLS regression analysis of drivers of customer retention

\begin{tabular}{lcc}
\hline Independent variable & Model 1-Retention & Model 2-WOM \\
\hline Customer satisfaction (CS) & $0.503^{\star \star \star}$ & $0.276^{\star \star \star}$ \\
Trust & $0.148^{\star \star \star}$ & $0.268^{\star \star \star}$ \\
$R^{2}$ & 0.381 & 0.253 \\
Adjusted $R^{2}$ & 0.378 & 0.249 \\
$F$ & $122.300^{\star \star \star}$ & $68.616^{\star \star \star}$ \\
\hline
\end{tabular}

${ }^{\star \star *} \mathrm{a}<0.01 \quad$ (Note: $\beta$ coefficients have been reported)

\section{DISCUSSION}

Effects of both satisfaction and trust on customer retention are found to be significant and positive. Therefore, previous research linking satisfaction to retention is confirmed. However, previous research has provided little empirical insight into the role of trust in retaining customers. These results confirm the expected positive effect of trust on retention. However, unlike in B-B relationships where trust has been found to be of utmost importance in maintaining long-term relationships, trust, in the $\mathrm{B}-\mathrm{C}$ context, is found to be a weaker predictor of retention than satisfaction. This contradicts some assertions in the literature that firms need to go beyond satisfaction to build trust in order to retain customers. The authors argue that this is likely to be a result of lower investment by both parties in B-C relationships relative to $\mathrm{B}-\mathrm{B}$ relationships. Since relationship termination costs are lower in the former than in the latter, customers may place less value on developing trust relationships with service providers in the $\mathrm{B}-\mathrm{C}$ context.

Indeed, it is also plausible that the nature of trust relationships depends upon the industry. It is known that trust plays a more important role in industries such as the financial services sector where customers may have concerns about the security of their funds. Furthermore, it is also known that online service providers require a high level of trust to attract customers, mainly due to the hidden nature of the customer-service provider interface. What the authors, based on their findings from the fixed line telephone sector, show, however, is that the long-term contractual nature of the relationship itself does not necessarily make trust more important than satisfaction.

It is also known that need for trust relationships can be dependent upon 
individual customers. Some have shown that trust is more important for more relationship-oriented customers than for transaction-oriented customers. ${ }^{28}$ Therefore, the possibility is not excluded that for some customers, trust in their service provider may be more important than satisfaction with their service provider in determining customer retention even in the context of fixed line telephones. As a whole, however, for the entire customer base, satisfaction is found to be a stronger driver of customer retention than trust.

Satisfaction and trust also have a significant positive effect on WOM. Again there is no evidence to support assertions made in the literature regarding the importance of trust over satisfaction. As a predictor of WOM, however, trust is only marginally weaker. Indeed, this is to be expected. Customers can be retained due to a multitude of reasons. But to make them say positive things about the service, they have to display true loyalty, a strong emotional attachment. A strong emotional attachment is likely to be preceded by a strong emotional response such as trust. Therefore, it is clear that ensuring both retention and WOM requires a dual strategy aimed at both increasing satisfaction and building a strong trust relationship.

While effect of trust on retention was substantially less than that of satisfaction, the qualitative data from the survey reinforced the importance of trust. Responses to the open-ended question requesting respondents to describe instances that led to dissatisfaction and/or loss of trust indicated that more than a third of the respondents who had a successful service recovery process ('satisfied with the service recovery process'), nevertheless ended up losing trust in their service provider. These findings have important implications for research and practice. The general trend in the literature has been to suggest that successful service recovery is the panacea to all service problems. Researchers have argued that a) service recovery can restore customers to a satisfied state or make them delighted ${ }^{29}$ and that $b$ ) customers who experience successful service recovery can sometimes be even more satisfied than those who did not experience a service failure in the first place. ${ }^{30}$ While both these points may be partly true, the full impact of service failure and recovery on trust appears to be different from that on satisfaction. Customers appear to be willing to accept the apology and compensation offered by the service provider as part of the recovery process, but may be less willing to trust their service provider to offer a trouble free service in the future. These findings are consistent with assertions made in the literature that in some service failure and recovery situations, customers may forgive the service provider, but do not forget the bad experience of failure. ${ }^{31}$ Therefore, even successful service recovery could lead to loss of trust and, consequently, increased likelihood of switching.

Thus, high customer satisfaction coupled with a relatively lower level of trust, may not ensure total customer commitment towards the service provider. This effect is illustrated in Figure 1, which is based on median split satisfaction and trust scores plotted against mean levels of customer retention. Figure 1 indicates how, at the high end of satisfaction, increasing trust further strengthens retention. Furthermore, among satisfied respondents, those with low levels of trust are significantly less likely to be retained than those who have high levels of trust (Mean Retention $_{\text {LowTrust }}=0.596<$ Mean Retention $\left._{\text {HighTrust }}=0.744, p<0.05\right)$. It also indicates that, while trust acts as a 


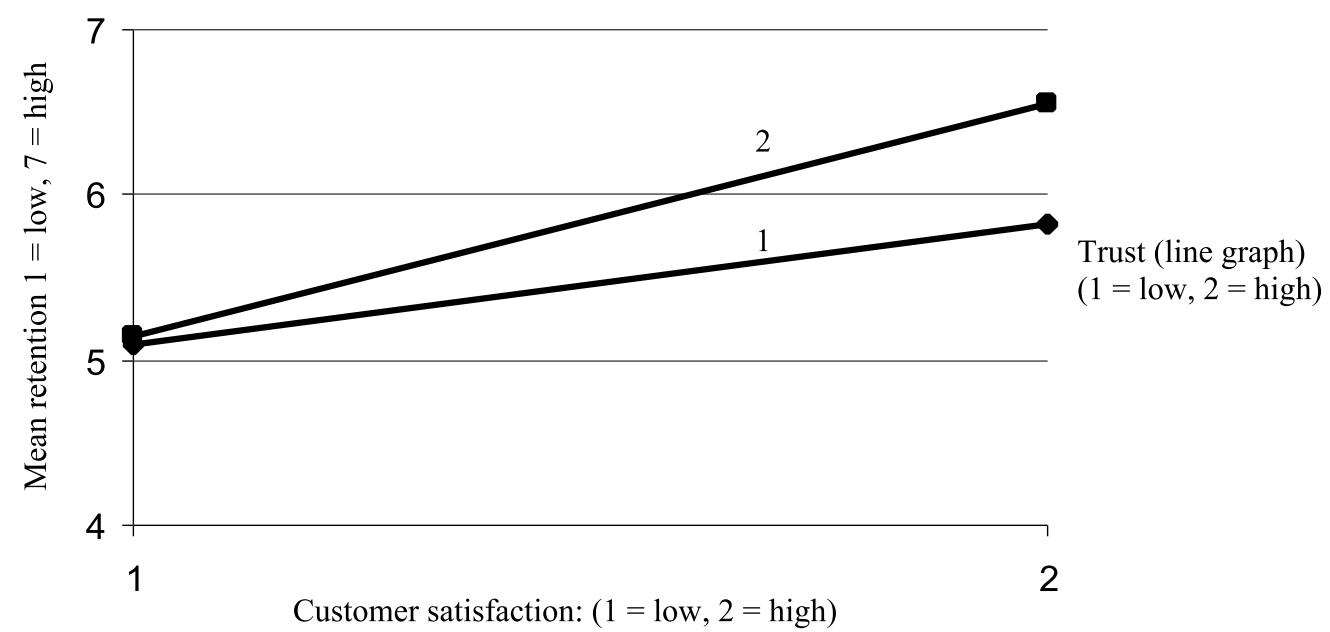

Figure 1 Mean retention across different levels of satisfaction and trust

complement to satisfaction for customers displaying high levels of satisfaction, trust has no significant impact in retaining dissatisfied customers.

Further, the satisfaction-trust discrepancy may at least partly depend on who initiates the service recovery process. Service provider initiated recovery may be possible in sectors with high customer contact, for example in the airline industry where a problem such as delayed departure is apparent to both the service provider and the customer. Service provider initiated recovery is, however, difficult or sometimes impossible in low customer contact industries such as fixed line telephony where failure is often associated with line defects and billing errors, errors which are noticed first and foremost by the customer. Therefore, in industries where a service failure goes unnoticed by the service provider, and has to be brought to the notice of the provider for corrective action, the negative impact on trust is likely to be stronger.

Indeed, Table 1 also indicates a high correlation between satisfaction and trust. This result is consistent with the extant literature. While satisfied customers in general are likely to trust their service provider, the above discussion illustrates an instance where customers could be satisfied, yet have lost trust in their service provider. In other words, it is possible for satisfaction and trust to diverge at least in some instances. These findings suggest the need for companies to have a combined strategy aimed at increasing both satisfaction and trust simultaneously. In a low customer contact context, this may entail elimination of the need for service recovery, or indeed, prevention of service failure in the first place.

\section{CONCLUSIONS}

Whereas in the past many studies on drivers of customer loyalty focused on a key customer perception such as satisfaction, the current study incorporates an additional construct that could be termed complementary to satisfaction. The paper reports that satisfaction is indeed an important driver of customer retention, even in a low customer contact, mass service setting. The effect of trust, though smaller, is nevertheless 
highly significant. As a driver of WOM, trust is found to be as important as satisfaction, indicating that a strong emotional response such as trust encourages people to make positive comments about their service provider.

Furthermore, while the literature often finds satisfaction and trust to be closely related, the current study finds some key differences too. While successful service recovery may satisfy the customer, it may not be possible to erase all the negative feelings associated with the initial service failure, especially where the failure is noted and the recovery process is initiated by the customer. Customers may accept the apology and the compensation and be entirely satisfied with the recovery process, but they may not necessarily forget the incident and trust the service provider not to make similar mistakes in the future. Given the proven link between trust and retention, service providers are well advised to be aware of the negative consequences that failure might have on customers' long-term attitude towards the service. Minimising failures is likely to both minimise costs of rectification and build trust. Thus, the findings add an important cautionary note to the tendency among practitioners to treat satisfactory service recovery as the panacea to all service problems.

\section{Limitations and future research}

This study was limited by the fact that it was based on cross-sectional data.

Further, the results were based on a single industry. Naturally, the findings are most likely to hold for similar low customer contact, mass service contexts with a continuous purchasing pattern. However, the high automation and low customer-staff contact of this context also makes the findings relevant for related industries where such phenomena are increasingly common due to the spread of technology. Nevertheless, the applicability of the findings to other contexts needs further research.

Also, while the authors have looked at satisfaction and trust as drivers of customer retention and WOM, there are indeed alternative drivers such as service quality and price, which have been looked at in the literature. Furthermore, some drivers of retention, such as switching costs, may not necessarily be drivers of WOM. While inclusion of a multitude of explanatory variables would have increased the holistic nature of the study, the authors' aim was specifically to compare the roles played by satisfaction and trust. It is also possible that satisfaction and trust can have nonlinear relationships, which may suggest, among other things, the possibility of satisfaction and trust having different levels of thresholds. While some literature has already suggested such possibilities, replication of those findings was beyond the scope of this paper.

\section{References}

1 Oliver, R. L. (1980) 'A cognitive model of the antecedents and consequences of satisfaction decisions', Journal of Marketing Research, Vol. XVII, November, pp. 460-469.

2 Anderson, E. W. and Sullivan, M. W. (1993) 'The antecedents and consequences of customer satisfaction for firms', Marketing Science, Vol. 12, No. 2, Spring, pp. 125-143.

3 Reichheld, F. F. and Sasser, W. E. (1990) 'Zero defections: Quality comes to services', Harvard Business Review, September-October, pp. 105-111.

4 Fornell, C., Ittner, C. D. and Larcker, D. F. (1995) 'Understanding and using the American customer satisfaction index (ACSI): Assessing the financial impact of quality initiatives', IMPRO 95, Juran Institute's Conference on Managing for Total Quality.

5 Jones, T. O. and Sasser, W. E. (1995) 'Why satisfied customers defect', Harvard Business Review, November-December, pp. 88-99.

6 Szymanski, D. M. and Henard, D. H. (2001) 'Customer satisfaction: A meta-analysis of the empirical evidence', Journal of the Academy of Marketing Science, Vol. 29, No. 1, pp. 16-35.

7 Geyskens, I., Steenkamp, J. E. M. and Kumar, N. (1998) 'Generalisations about trust in marketing 
channel relationships using meta-analysis',

International Journal of Research in Marketing, Vol. 15, pp. 223-248.

8 Hart, C. W. and Johnson, M. D. (1999) 'Growing the trust relationship', Marketing Management, Spring, pp. $8-19$.

9 Gremler, D. D. and Brown, S. W. (1996) 'Service loyalty: Its nature, importance, and implications', in Edwardson et al. (eds) 'Advancing service quality: A global perspective', International Service Quality Association, pp. 171-180.

10 Bansal, H. S. and Taylor, S. F. (1999) 'The service provider switching model (SPSM): A model of consumer switching behaviour in the service industry', Journal of Service Research, Vol. 2, No. 2, pp. 200-218.

11 Gremler and Brown (1996) op. cit.

12 Mital, V. and Kamakura, A. (2001) 'Satisfaction, repurchase intent, and repurchase behaviour: investigating the moderating effect of customer characteristics', Journal of Marketing Research, Vol. XXXVIII, February, pp. 131-142.

13 Reichheld and Sasser (1990) op. cit.

14 Fornell, C. (1992) 'A national customer satisfaction barometer: The Swedish experience', Journal of Marketing, Vol. 56, January, pp. 6-21.

15 Schneider, B. and Bowen, D. (1999) 'Understanding customer delight and outrage', Sloan Management Review, Fall, pp. 35-45.

16 Hart and Johnson (1999) op cit.

17 Morgan, R. M. and Hunt, S. D. (1994) 'The commitment-trust theory of relationship marketing', Journal of Marketing, Vol. 58, July, pp. 20-38.

18 Gremler and Brown (1996) op. cit.
19 Hart and Johnson (1999) op. cit.

20 Geyskens, et al. (1998) op. cit.

21 Hart and Johnson (1999) op. cit.

22 Ibid.

23 Keaveney, S. M. (1995) 'Customer switching behaviour in service industries: An exploratory study', Journal of Marketing, Vol. 59, pp. 71-82.

24 Gremler, D. D. and Gwinner, K. P. (2000) 'Customer-employee rapport in service relationships', Journal of Service Research, Vol. 3, No. 1, pp. 82-104.

25 Cronin, J. J., Brady, M. K. and Hult, G. T. M. (2000) 'Assessing the effects of quality, value, and customer satisfaction on consumer behavioural intentions in service environments', Journal of Retailing, Vol. 76, No. 2, pp. 193-218.

26 Morgan and Hunt (1994) op. cit.

27 Moorman, C., Deshpande, R. and Zaltman, G. (1993) 'Factors affecting trust in market research relationships', Journal of Marketing, Vol. 57, January, pp. 81-101.

28 Garbarino, E. and Hohnson, M. S. (1999) 'The different roles of satisfaction, trust, and commitment in customer relationships', Journal of Marketing, Vol. 63, pp. $70-87$.

29 Johnston, R. and Fern, A. (1999) 'Service recovery strategies for single and double deviation scenarios', The Service Industries Journal, Vol. 19, April, pp. 69-82

30 Brown, S. W. (2000) 'Practicing best in class service recovery', Services Marketing, Summer, pp. 8-9.

31 Levesque, T. J. and McDougall, G. H. G. (2000) 'Service problems and recovery strategies: An experiment', Canadian Journal of Administrative Sciences, Vol. 17, No. 1, pp. 20-37. 